\title{
Microstructure Evolution and Distribution of Mechanical Properties in Shielded Metal Arc Welded Dissimilar DSS 2205 and HY80 Joints
}

\author{
Sunoto Mudiantoro ${ }^{1}$, Winarto Winarto ${ }^{1, *}$, and Herry Oktadinata $^{1}$ \\ ${ }^{1}$ Dept. of Metallurgy and Materials Eng., Faculty of Engineering, Universitas Indonesia, Indonesia
}

\begin{abstract}
Dissimilar welding is a unique and complex process because in each zone in the different welding area have unique structures and characteristics. The modified structure may have a significant effect on weld metal properties. In this research, the primary objective is to investigate the microstructure evolution and hardness distribution mode of a different joint HY80 steel plate and Duplex type 2205 welded by using thick weld or shielded metal arc weld (SMAW). The microstructure of weld metal zones was observed. The test plates were welded in both butt joint and fillet joint by using E309L filler metal. It was found that the 309L electrode provides the equilibrium between austenite and ferrite phase in the different weld metal zones of DSS 2205 and HY80 steel joint. The results show that hardness distribution of different joint of both butt weld and fillet weld presents sinusoidal trend, where hardness in HAZ is highest. The peak value of hardness appeared in HY 80 base metal near the fusion line. The microstructure of base metal DSS 2205 shows fine grains of ferrite and austenite grains with dark and light shades respectively. The microstructure of weld metal shows coarse grains of austenite along with some slag inclusions as dark spots. The Heat Affected Zone of HY80 steel plate shows coarse grains of austenite and ferrite, while the heat affected zone of DSS 2205 shows thin fusion line with coarse grains of ferrite as dark zones and coarse grains of austenite as light zones. There is, a degree of variation in weld metal ferrite content was observed. Keywords: Duplex Stainless Steel, HY80, SMAW, Dissimilar Joint, Hardness, and Impact Toughness.
\end{abstract}

\section{Introduction}

The HY-80 steel is fine-grained structural steel that designed to achieve a high yield strength that can resist the permanent plastic deformation. This steels were used in marine industries, specifically of pressure hulls for the submarine and recently used in maritime industries. HY 80 have excellent corrosion resistance and requires careful consideration of the welding procedures, joint design to account for distortion, microstructure changes, stress concentration, and filler metal selection [1].

The microstructure formed in the welding process is related to the thermal cycle and the alloying elements composition of the base material. The microstructure that is created will vary in weld pool, heat affected zone, fusion line, and base materials. The microstructure weld metal will determine the mechanical properties of the welding results.

The welding process on the HY- 80 steel plate raises concerns about the formation of untemper martensite in the heat-affected zone (HAZ), and fusion zone (FZ) HY80 had a steel hardenability when heat treated [2]. The welding process can create rapid cooling with the steep temperature gradients so that that martensite can be formed [3]. In the naval shipbuilding industry, HY-80 steel is used in thick plates or large welds so that special welding procedures are required.

Duplex stainless steels (DSS) have 50/50 mix ratio microstructure of ferrite and austenite when in the fact commercial steel, the ratio is probably 60/40 [5]. DSS has high chromium contents $(19-32 \%)$, the amount of molybdenum (2-5\%), and nickel contents lower than austenitic stainless steels. DSS has roughly twice the strength than austenitic stainless steels [6].

DSS classification is based on alloying content and corrosion resistance. Duplex standard refers to $22 \%$ chromium values, such as 2205 type, the most widely used. The transformation of the austenite/ferrite structure affects the mechanical properties and corrosion resistance. When the austenite content is lower than the ferrite, this will encourage the emergence of precipitation in the intermetallic phase, such as $\sigma$ phase. This phase affects the corrosion resistance and toughness in the duplex material. [7]. Therefore, it is essential to be careful selection of parameters process and welding materials, to reduce the effects of corrosion and toughness reduction.

Mechanical properties, phase transformations and microstructures in dissimilar welding metals are exciting to observe because there are so many unique and

Corresponding author: winarto@metal.ui.ac.id 
deserving phenomena to examine carefully compared to similar welding. These differences are inseparable from the influence of filler metals or electrodes which are suitable for metals to be joined $[8,9]$.

In order to observe the relationship between high strength steel structures and stainless steel (DSS) duplex structures, the research study is to produce connections with different electrodes of chemical properties and composition with duplex stainless steels electrode and austenitic stainless steels electrode, with SMAW processes, using different welding materials. Mechanical properties and microstructure of weld joint will be characterized in research.

\section{Experimental Procedure}

The parent metals applied in this study were HY 80 steel and 2205 duplex stainless steel. The materials made in the form of steel plates with a thickness of $12 \mathrm{~mm}$. Referring to Table 1, the elemental composition of HY80 meets to standard specification according to MIL-S$16216 \mathrm{~K}(\mathrm{SH})$ [2], and Duplex Stainless Steel 2205 meets to standard specification according to ASTM A240 [4]. The multipass SMAW process worked to join this combination, by using an austenitic electrode (E309L). The elemental composed of base metal was conducted by optical emission spectroscopy (OES), and the result is provided in Table 1 .

Table 1. Elements of Material investigated (wt,\%)

\begin{tabular}{|c|c|c|c|l|c|}
\hline Material & $\mathbf{C}$ & \multicolumn{1}{|c|}{ Si } & \multicolumn{1}{|c|}{ Mn } & \multicolumn{1}{|c|}{ S } & P \\
\hline HY 80 & 0,14 & 0,22 & 0,28 & 0,002 & 0,004 \\
\hline DSS 2205 & 0,02 & 0,39 & 1,65 & 0,0004 & 0,003 \\
\hline E 309 L & 0,02 & 0,5 & 1,27 & 0,011 & 0,022 \\
\hline Material & $\mathbf{C r}$ & $\mathbf{N i}$ & $\mathbf{M o}$ & $\mathbf{C u}$ & $\mathbf{R E M ~ F e}$ \\
\hline HY 80 & 1,48 & 2,70 & 0,43 & 0,25 & 95,07 \\
\hline DSS 2205 & 22,3 & 4,31 & 2,80 & 0,5 & 66,86 \\
\hline E 309 L & 22,0 & 12,0 & 0,75 & 0,35 & 63,12 \\
\hline
\end{tabular}

In this research, HY-80 is welded with an AWS E $309 \mathrm{~L}$ welding wire. The E $309 \mathrm{~L}$ welding wire has a lower $\mathrm{C}$ and amount of Nickel content. To aid in dilutive effect during welding. The critical function of the electrode material is to initiate acicular ferrite nucleation. In the presence of oxides and a rapid cooling process will form acicular ferrite which can increase the formation of this critical nucleation site.

The received plate was cut to the dimensions of 300 $\times 150 \times 12 \mathrm{~mm}$, and then single $\mathrm{V}$-groove butt joint configuration with an angle of $60^{\circ}$ was welded as shown in Figure 1. The multi-pass welds were made by using SMAW with the horizontal position (2G). Electrode type E309L of $3.2 \mathrm{~mm}$ diameter was applied to weld specimens test. The schematic of the weld specimen is in the Figure. 1.

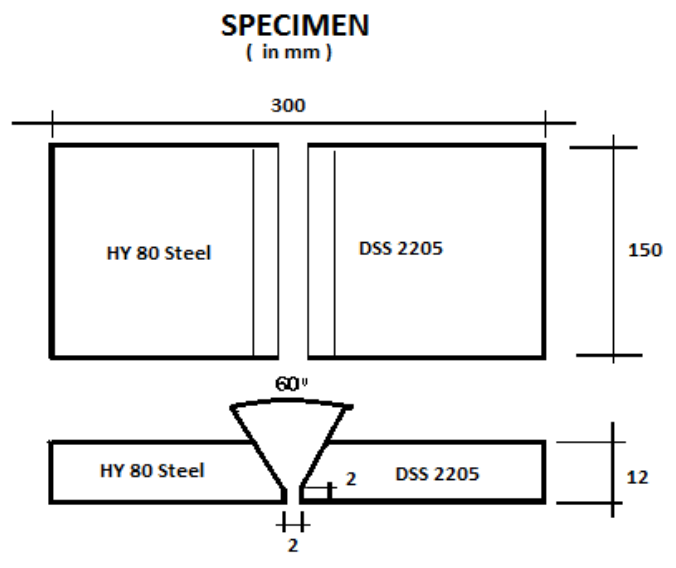

SPECIMEN FILLET JOINT

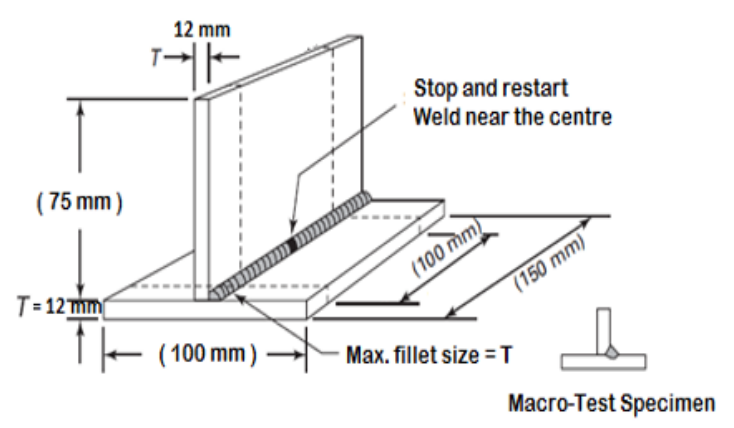

Fig. 1. The Schematic of Welded joint a) Butt weld and b) Fillet Weld [4].

The parameters of the different joint used in this experiment can be seen in Table 2. The welding parameters in this experiment are derived from industrial experiences and the works of literature.

Table 2. The Welding parameters of dissimilar joint

\begin{tabular}{|l|c|c|c|c|c|}
\hline Method & Electrode & $\begin{array}{c}\text { Wire } \\
\text { Dia. } \\
(\mathbf{m m})\end{array}$ & $\begin{array}{c}\text { Speed } \\
(\mathbf{m m} / \mathbf{m i} \\
\mathbf{n})\end{array}$ & $\begin{array}{c}\text { Voltage } \\
(\mathbf{V})\end{array}$ & $\begin{array}{c}\text { Current } \\
(\mathbf{A})\end{array}$ \\
\hline Thickweld & E 309L & 3,2 & $85-150$ & $21-22$ & $85-100$ \\
\hline
\end{tabular}

The micrograph of the joint can be shown in Fig. 2

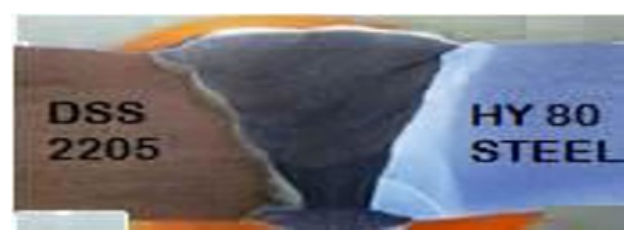

Fig. 2. Macrograph of the dissimilar weld joint

To obtain the mechanical properties of the material that has been welded, a mechanical test is performed. Whereas to find out the microstructure that occurs after the welding process, metallurgical testing is carried out. 
Microstructure observation using an optical microscope with an enlargement of 200, 500 and 1000 . The material preparation that will be observed with an optical microscope includes griding 200, 400, 600, 800, and 1200 after that was polished. Then etched with 2205 DSS steel etched with $15 \% \mathrm{NaOH}$, welded pool with $12 \%$ Oxalate and 3\% Nital for HY 80 steel [4].

The element composition from weld specimens used optical emission spectroscopy (OES) and energydispersive x-ray spectroscopy (EDS) for inclusion. Microstructure observation of weld specimens using optical microscopy (OM) and scanning electron microscopy (SEM). Austenite and ferrite volume fractions are calculated by analyzing images using a computer program.

The mechanical properties of different metal joints were tested by doing microhardness and Charpy tests. Measurement of Vickers hardness was taken on Buehler Microhardness below 300 g/f, (ASTM E92-82 standard) [4]. Hardness testing is carried out on $2 \mathrm{~mm}$ line from the upper and root surfaces of the plate. The Vickers hardness indentation tested in Figure 3.

a)

b)
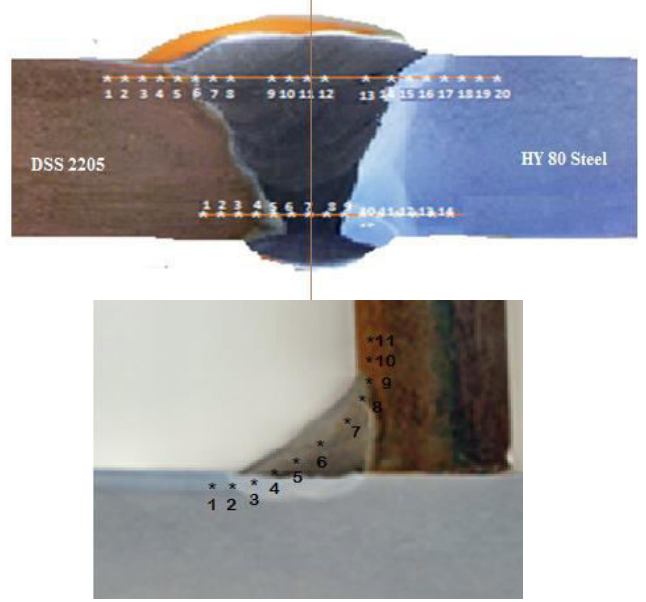

Fig. 3. Indentation of microhardness Vickers test of the weldment: a) butt weld; and b) fillet weld

Furthermore, to determine and observe the toughness of the welding material, the impact toughness is tested at room temperature. Figure 3 Charpy Impact Specimens in WM, FL, and HAZ.

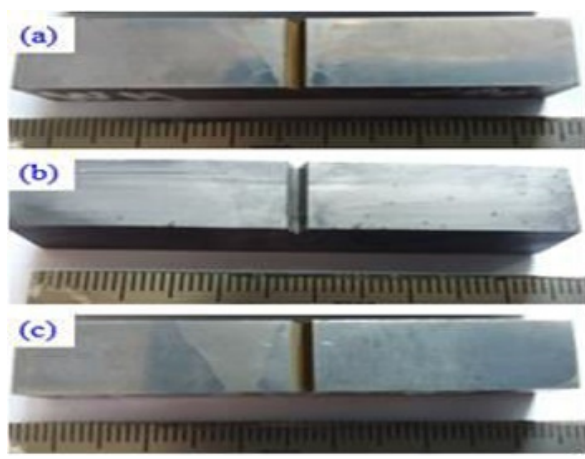

Fig. 4. Specimens of Charpy impact test with V-notch at (a) WM, (b) FL, (c) HAZ

\section{Result and Discussion}

\subsection{Microstructure}

The microstructure base metal of the 2205 steel plate and the HY80 steel plate is shown in Figure $5 \mathrm{a}$ ) and b). In Base Metal DSS 2205, there are two types of grain structures with longitudinal and parallel directions in the rolling direction, namely austenite phase $(\gamma)$ with an average number of $55.6 \%$ distributed in the ferrite matrix $(\delta)$ with an average number of $44,4 \%$ austenite.

a)

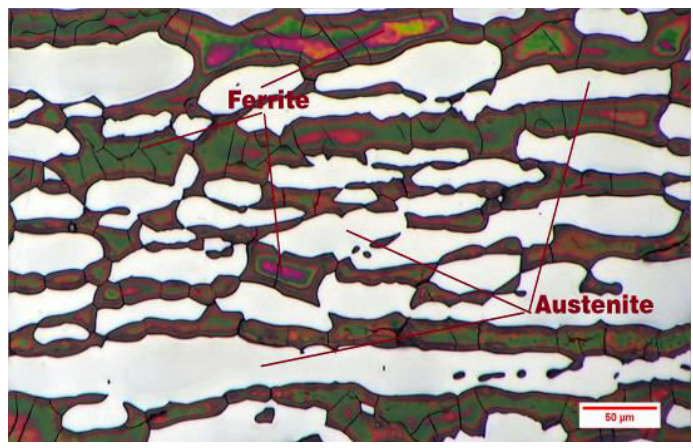

b)

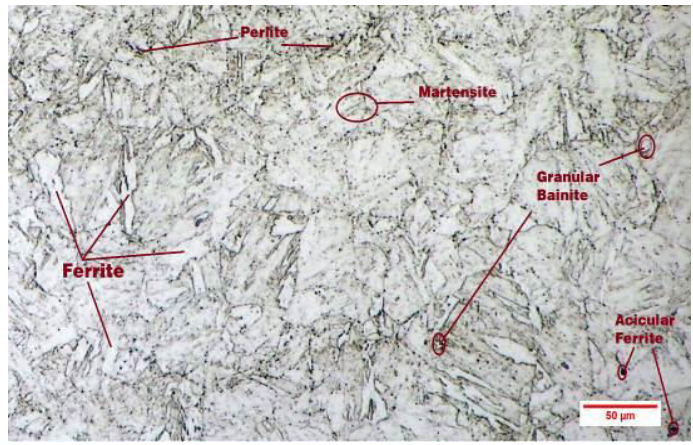

Fig. 5. Base Metal Steel Plate of a)2250 and b) HY 80

Whereas, on HY80 plate steel base metal (HY80 $\mathrm{BM})$, the microstructure is formed from the rolling process. The phase in the primary structure consists of ferritic (white area) as a matrix, and pearlitic phase (dark area). Besides that, we also found a formation of martensite, bainite and acicular ferrite which was caused by the TMCP.

During welding, there is a thermal welding cycle and a fast cooling rate that affects the microstructure evolution and distribution of mechanical properties in each zone. In the heat-affected zone (HAZ) produced by both sides of different welding metals, have different characteristics. This zone is close to the fusion limit. These zones occur in the process of metallurgical transformation which has an essential effect on the weldability of dissimilar weld joints.

Due to the rapid cooling rate caused by thermal cycle from the welding process, the carbon migration can cross the fusion boundary of the HY80 steel plate into the weld metal.

Figure 6 shows the carbon presented (C in HY80 WM), showing the carbon affinity for the high inclusion in welding metal. Furthermore, the rapid cooling rate of the HY80 liquid and steel dilution pool produces segregation of alloy elements beside a fusion line. There 
are non-metallic inclusions in WM near HY80 side. The presence of chrome carbide around line fusion will improve mechanical properties.

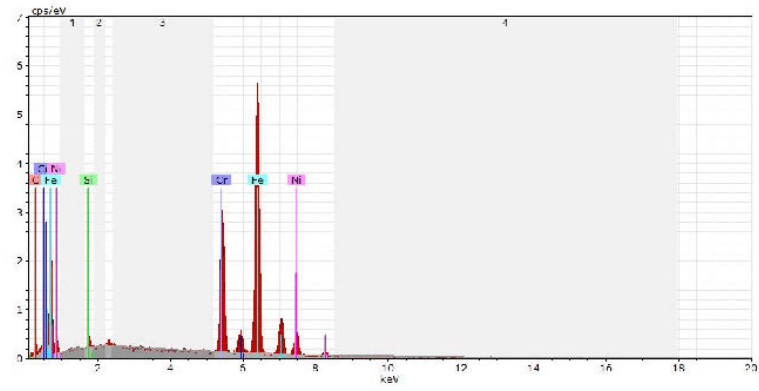

Spectrum: Äccquisition

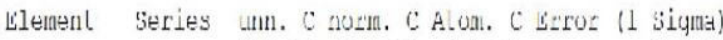

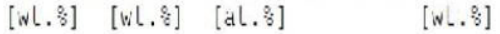

Carbon K-scrics $\quad 5.13 \quad 3.94 \quad 22.38 \quad 1.14$

silicon R-scrics $0.60 \quad 0.70 \quad 1.13 \quad 0.01$

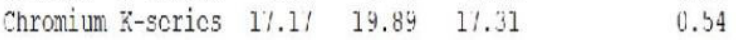

lroa K-series $\quad 55.73 \quad 61.55 \quad 52.30 \quad 1.60$

$\begin{array}{llllll}\text { Nickel Keries } & 7.71 & 8.93 & 6.98 & 0.34\end{array}$

Total: $86.34 \quad 100.00 \quad 100.00$

Fig. 6. EDX analysis is showing non-metallic inclusions in WM HY80 steel plate.

In Figure 7a there is a HAZ region on the side of the steel plate HY 80 (HAZ), the area where microstructure recrystallization occurs. In the HAZ close to the fusion line (FL) we can see that the granules are composed of sizeable structured ferrite (GCF), and a small amount of perlite $(\mathrm{P})$ phase. The result is in line with the theory of the effect of high heat from the welding process which causes the cooling rate to run slowly. Slow cooling rates make grains grow. From the results, Metallographic examination revealed that the inside of the weld pool and fusion line (FL) formed a new boundary, the type II boundary (being a typical characteristic in different metal connections) which is a narrow zone, about $50 \mu \mathrm{m}$. This area is the place where phase transformation occurs; there is a difference in the crystal structure between the growing boundaries and developing boundaries.

Figure $7 \mathrm{~b}$ shows the phase microstructure in the HAZ different welding zone on 2205, which is formed by the ferrite matrix (around 60\% ferrite phase), and consequently, the austenite phase is present in the region (white area) as a little amount. It is due to the temperature of the heat cycle in the welding process, where the austenite phase is converted to the ferrite phase.

There is also an area between fusion lines and type II boundaries. In this area the austenitic phase of weld pool is transformed into planar (epitaxial grow) and then develops into cellular (widmanstaten), then becomes the dendritic columnar (seen in microstructure 7b) and equiaxed dendritic in the solid state during cooling of the weld. It allows the growth of austenite grains across the fusion boundary to the HAZ region on the side of 2205 DSS.

In a solid state during cooling, at the area around of fusion line (FL), the grain boundary is formed which allows the growth of austenite grains and cross the fusion boundary ( Figure 9 ).

a)

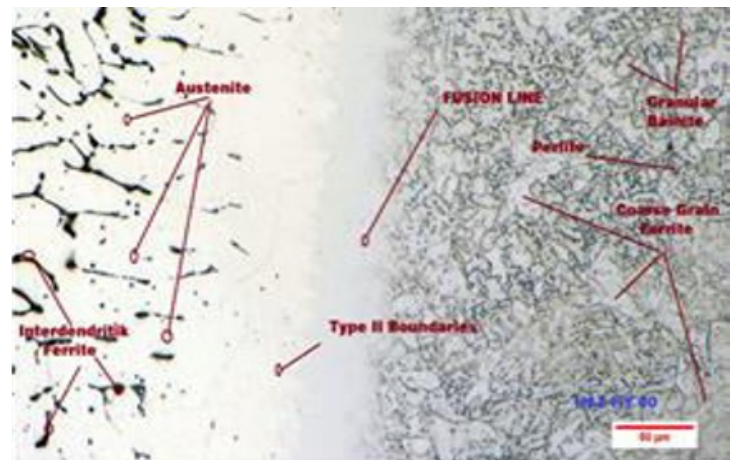

b)

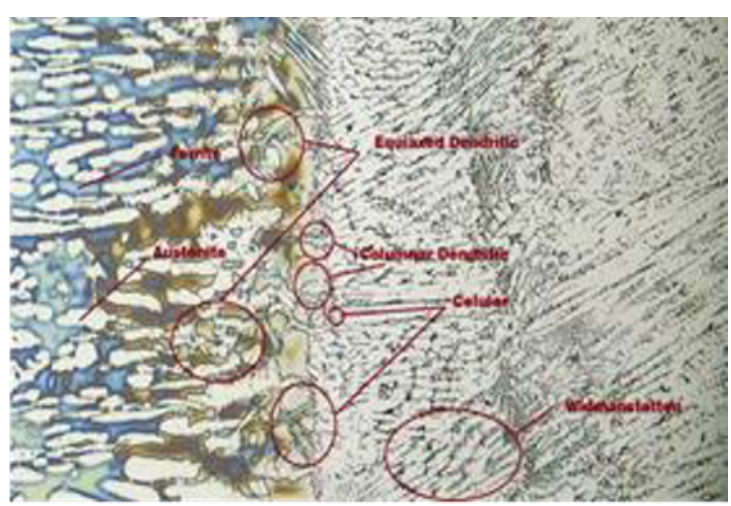

Fig. 7. Weld pool, Fusion Line and HAZ of Dissimilar SMAW of a) HY80 Steel and b) DSS-2205

The weld pool becomes elliptically shaped due to slow welding speed like in Figure $7 \mathrm{~b}$. The columnar grains are also essentially straight to grow perpendicular to the pool boundary, as shown schematically in Figure $7 \mathrm{~b}$.

The columnar grains are also grown perpendicular to the pool boundary shape, as shown in figure $7 \mathrm{~b}$. Epitaxial growth is formed in the area between the fusion line and weld pool.

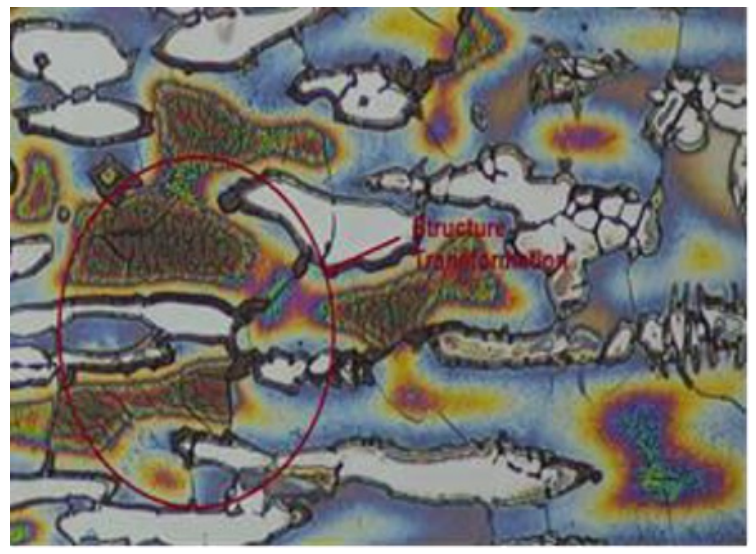

Fig. 8. Austenite phase transformation 


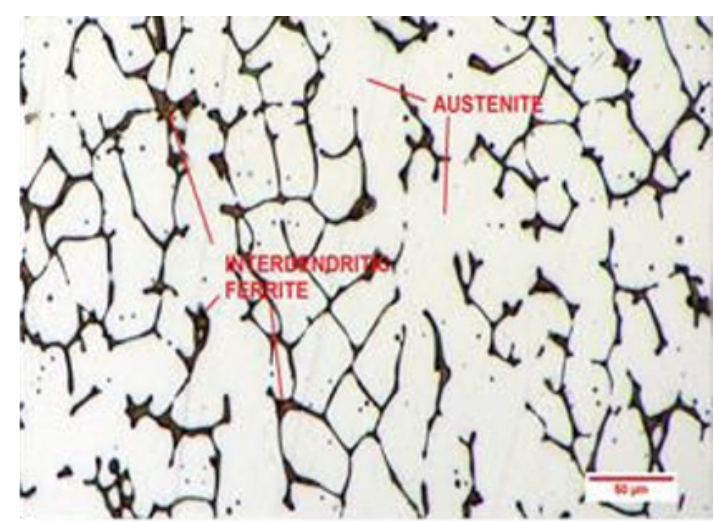

Fig. 9. Weld Metal micrograph of Dissimilar Welds between HY80 Steel and DSS-2205

The microstructure of E309L WM that observed by $\mathrm{OM}$ is shown in Fig.10. The weld metal structure filled with electrode E309L consists of the ferrite phase, interdendritic and austenite phases as a matrix.

\subsection{Mechanical Properties}

\subsubsection{Hardness Distribution}

Significant hardness distribution in the result of dissimilar welding of 2205 DS Steel plate with HY 80 steel plate is induced by the transfer heat cycle from the weld metal center to the parent metal during welding. The hardness in weld pool of the dissimilar weld will decrease as heat input increases. In this dissimilar welding, there is a hardness reduction in the welding center but not lower than the hardness of the HY80 steel plate parent metal. The hardness properties in the weld portion of DSS 2205 looks higher, especially near the fusion line, because of the excessive ferrite content in the HAZ welding will form $\mathrm{Cr} 2 \mathrm{~N}$ inclusion. This inclusion formation occurs due to manual welding instability (SMAW), so that when the arc energy is low $\mathrm{Cr}$ and $\mathrm{N}$ form $\mathrm{Cr}_{2} \mathrm{~N}$.

Figure 10 shows the microhardness distribution of dissimilar stick weld DSS2205 plate and HY 80 Steel plate Type butt joint. The hardness in weld metal is higher than HY80 metal parents, which is proven due to $\mathrm{Cr}$ and Mo element in the chemical composition of filler E309L.

The increased hardness in the 2205 HAZ DSS is caused by many factors including the increase in ferrite content and shrinking grain size, an effect of the thermal cycle of the welding process. Furthermore, the lowest hardness was recorded in the area between FL and CGHAZ in HY80 HAZ side due to grain growth of austenite phase and phase austenite cross to the boundary in this zone.

Figure 10 shows the hardness distribution of the weld metal interface. The peak hardness on the steel HY80 metal side is observed in the narrow area among the type II boundary zone and the fusion line, which is related to the microconstituents that presence in this zone, because of two things. The first is the migration of the austenite phase from weld metal to the fusion line and the carbon element from HY80 steel to the weld metal area. Besides that, the formation of chrome carbide around the fusion line also influences the hardness on the side HAZ of the HY80 steel.
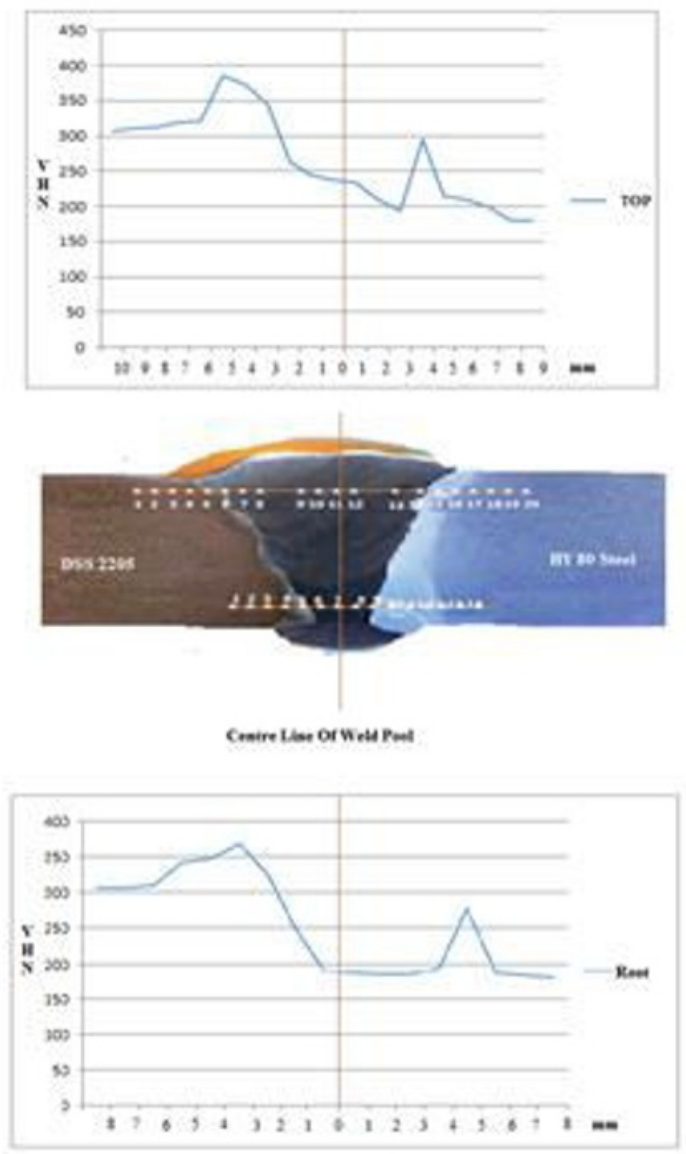

Fig. 10. Hardness distribution of Dissimilar weld on a DSS2205 plate and HY-80 plate with a butt joint type: (a) Top, (b) Root

Figure 10 shows the microhardness distribution of dissimilar stick weld DSS2205 plate and HY 80 Steel plate Type butt joint. The hardness in weld metal is higher than HY80 metal parents, which is proven due to $\mathrm{Cr}$ and Mo element in the chemical composition of filler E309L.

The increased hardness in the 2205 HAZ DSS is caused by many factors including the increase in ferrite content and shrinking grain size, an effect of the thermal cycle of the welding process. Furthermore, the lowest hardness was recorded in the area between FL and CGHAZ in HY80 HAZ side due to grain growth of austenite phase and phase austenite cross to the boundary in this zone.

Figure 11 shows the hardness distribution of the weld metal interface. The peak hardness on the steel HY 80 metal side is observed in the narrow area among the type II boundary zone and the fusion line, which is related to the microconstituents that presence in this zone, because of two things. The first is the migration of the austenite phase from weld metal to the fusion line and the carbon element from HY80 steel to the weld metal area. Besides that, the formation of chrome carbide around the fusion 
line also influences the hardness on the side HAZ of the HY80 steel.

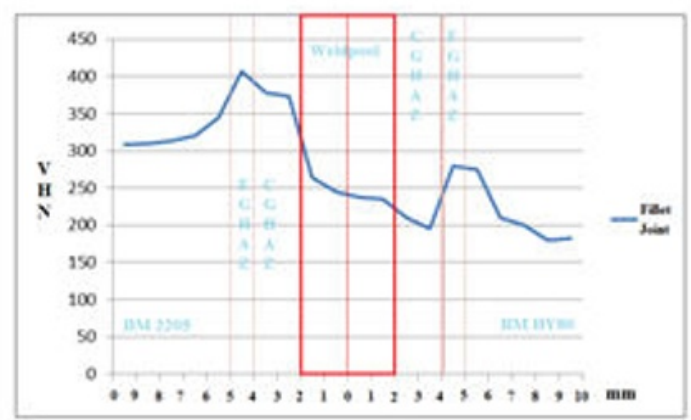

Fig. 11. Hardness distribution of dissimilar weld between DSS-2205 and HY-80 steel with the joint fillet type

In the FGHAZ area, the SMAW Dissimilar Welding between HY 80 and DSS 2205 provides higher hardness when compared to the hardness of the parent metal region, due to the strain induction during weld freezing. Also, it is also influenced by the formation of residual stresses and fast thermal cycles in welds. The creation of an excellent grain size because of the rapid rate of cooling contributes to increase hardness, due to dislocations in this area.

\subsubsection{Impact Toughness}

The impact energy absorbed in the different welding zone is shown in Fig. 12.

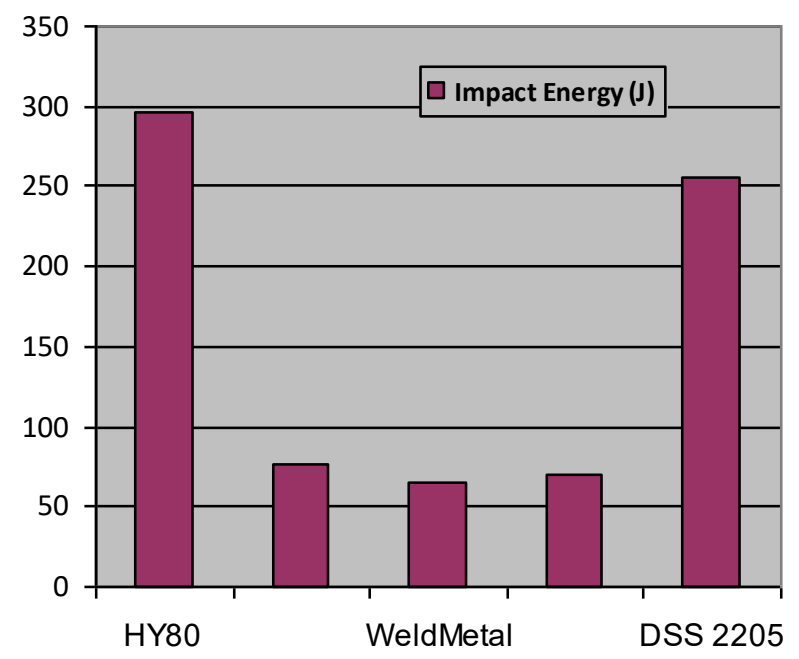

Fig. 12. Charpy impact values of dissimilar weld metals

Impact testing is carried out in room temperature conditions. The impact toughness of the base metal is more toughness than the HAZ, which is associated with the presence of the hard constituents and coarse grain in the HAZ. Furthermore, the heat affected zone is more resilient than weld metal one; this is related to the presence of element Mo which is quite high in the filler metal E309L. Base Metal HY 80 exhibits the highest due to the presence of acicular ferrite to absorb impact energy.

\section{Conclusion}

Diffusion of carbon from base metal to the weld metal due to the rapid cooling rate caused by thermal cycle from the welding process, the carbon migration can cross the fusion boundary of the HY80 steel plate into the weld metal.

The type II boundary which has a narrow zone about $50 \mu \mathrm{m}$ was formed between fusion line and weld metal. Microconstituents are present in a narrow region between fusion lines and type II boundaries, and it changed their mechanical properties.

The fine grain HAZ areas on both sides have the highest hardness distribution of dissimilar joint. The impact energy absorbed in BM is higher than another zone in the dissimilar welding zone at room temperature because of the brittle zone existed in the HAZ and the weld metal.

The E309L electrodes are recommended to weld the dissimilar metals between Duplex Stainless Steel 2205 and HY80 steel plate.

We want to express our gratitude for the support of research funding from the Directorate of Riset dan Pengabdian Masyarakat (DRPM) Universitas Indonesia through the PITTA Program. The Contract No. 2558/UN2.R3.1/HKP.05.00/2018.

\section{References}

1. Brahim Belkessa, Djamel Giroud, Naima Ouali, Billel Cheniti. "Microstructure and Mechanical Behavior in Dissimilar SAF 2205/API X52 Welded Pipes", Acta Metallurgical Sinica (English Letters), (2016)

2. Winarto Winarto, Herry Oktadinata, Eddy S. Siradj. "Microstructure and hardness properties of butt and fillet GMAW welded joint s on HY80 high strength steel plate", AIP Publishing, (2018)

3. Kou, Sindo."Welding metallurgy" the 2nd ed. A Wiley-Interscience publication, (2002).

4. ASTM Standards, "Metal Test Methods and Analytical Procedures" Volume 03.01, (2001).

5. B.I. Mendoza, "Dissimilar Welding of Superduplex Stainless Steel/HSLA Steel for Offshore Applications Joined by GTAW," Engineering 2 (2010) 520-528.

6. H. Tasalloti, "Effect of heat input on dissimilar welds of ultra high strength steel and duplex stainless steel": microstructural and compositional analysis, Materials Characterization 123 (2017) 29-41.

7. J. Pilhagen, "Influence of nickel on the toughness of lean duplex stainless steel welds," Materials Science and Engineering A $\mathbf{6 0 2}$ (2014) 49-57.

8. A. Vinoth Jebaraj, "Influence of microstructural changes on impact toughness of weldment and base metal of duplex stainless steel AISI 2205 for lowtemperature applications", Procedia Engineering 64 (2013) 456-466. 
9. A. Vinoth Jebaraj, "Investigations on anisotropy behavior of duplex stainless steel AISI 2205 for optimum weld properties", Procedia Engineering 173 ( 2017 ) $883-890$

10. A. Vinoth Jebaraj, "Weldability, machinability, and surfacing of commercial duplex stainless steel AISI2205 for marine applications-a recent review", Journal of Advanced Research 8 (2017) 183-199

11. J. Verma, Effect of welding processes and conditions on the microstructure, mechanical properties and corrosion resistance of duplex stainless steel weldments - A review, Journal of Manufacturing Processes 25 (2017) 134-152.

12. M. Sadeghian, "Effect of heat input on microstructure \& mechanical properties of dissimilar joints between super duplex stainless steel and high strength low alloy steel" $l$, Materials, and Design 60 (2014) 678-684.

13. Z. Zang, "Microstructural characterization and electron backscatter diffraction analysis across the welded interface of duplex stainless steel," Applied Surface Science 413 (2017) 327-343. 